\title{
Class II HLA antigens in multiple sclerosis
}

\author{
D H MILLER, * R W HORNABROOK, * J DAGGER, $\dagger$ R FONG $\dagger$ \\ From the Departments of Medicine, ${ }^{*}$ and Immunohaematology, $\dagger$ Wellington Hospital, Wellington 2, New \\ Zealand
}

SUMMARY HLA typing in Wellington revealed a stronger association of multiple sclerosis with DR2 than with DQw1. The association with DQw1 appeared to be due to linkage disequilibrium of this antigen with DR2. These results, when considered in conjunction with other studies, are most easily explained by the hypothesis that susceptibility to multiple sclerosis is influenced by multiple risk factors, with DR2 being an important risk factor in Caucasoid populations.

The cause of multiple sclerosis is unknown. Current evidence suggests that both environmental and genetic factors are of aetiological importance. Multiple sclerosis occurs most frequently in temperate zones, though the prevalence in such climatic regions varies for different ethnic groups. Thus, the disease is common in Caucasians in Northern Europe, North America and Australasia, but is much less common in Orientals' and Polynesians ${ }^{2}$ living in the same latitude and environment. Strong evidence implicating genetic factors in susceptibility to multiple sclerosis has come from the Canadian twin study. ${ }^{3}$ This population-based study found concordance for multiple sclerosis in $1.9 \%$ of non twin siblings, $2.3 \%$ of dizygotic twins and $26 \%$ of monozygotic twins.

The search for a multiple sclerosis susceptibility gene has been encouraged by the discovery in the last 16 years of a number of consistent associations of HLA antigens and multiple sclerosis. The initial associations in Caucasoid populations were with the Class I antigens $\mathrm{A} 3^{4}$ and $\mathrm{B} 7 .^{5} \mathrm{~A}$ stronger association with the Class II antigen DR2 (which is in linkage disequilibrium with $\mathrm{A} 3$ and $\mathrm{B} 7$ ) was subsequently identified. This association has been observed in Caucasians in the United Kingdom, ${ }^{6}$ Europe, ${ }^{7}$ North America, ${ }^{8}$ Australia ${ }^{9}$ and New Zealand. ${ }^{2}$ On average, about $50-70 \%$ of Caucasoid multiple sclerosis patients are DR2 positive compared with $16-30 \%$ of controls.

The association of DR2 with multiple sclerosis is not seen in the Aberdeen region, ${ }^{10}$ or the Orkney Islands, " areas where the prevalence of multiple sclerosis is exceptionally high. The lack of an association is due to the unusually high frequency of the DR2 antigen in the normal population of these regions

Address for reprint requests: Dr D H Miller, Department of Medicine, Wellington School of Medicine, Wellington Hospital, Wellington 2, New Zealand.

Received 25 October 1988.

Accepted 19 December 1988
( $41 \%$ in Aberdeen and $50 \%$ in the Orkneys). However, an association in Aberdeen has been reported with the more recently defined Class II antigen, DQw1." The same association has since been reported elsewhere. ${ }^{1213}$

To assess the relative significance of DR2 and DQwl in relation to multiple sclerosis, we tissue typed the Class II DR and DQ antigens in Caucasoid multiple sclerosis patients in the Wellington region. The findings were compared with healthy Caucasoid controls. HLA data were also collected in Maori controls. A comparison of the findings in Caucasoid and Maori controls was undertaken, in view of the known rarity of multiple sclerosis in Maoris, ${ }^{214}$ and because a previous study demonstrated different antigen frequencies between these ethnic groups, in particular a low frequency of DR2 in Maoris. ${ }^{2}$

\section{Methods}

A blood sample for tissue typing was taken from multiple sclerosis patients who were seen as part of a review of all identifiable cases in the Wellington region in 1983. The method of case ascertainment is detailed elsewhere. ${ }^{2}$ HLA Class I and Class II typing was performed by a standard lympho-cytotoxicity test following $\mathrm{T}$ and $\mathrm{B}$ cell lymphocyte separation using a nylon wool column. Only the results of Class II typing are discussed in this paper. The typing sera used defined 11 HLA-DR and 3 HLA-DQ specificities. The Caucasoid controls comprised 117 normal healthy blood donors. The Maori control population comprised 82 individuals who self identified as Maoris. The multiple sclerosis group comprised 144 Caucasians with clinically definite or probable multiple sclerosis using the McDonaldHalliday criteria. ${ }^{15}$ (No Maori patients fulfilling these criteria were identified.)

Statistical evaluation of the data was performed using the chi-squared test with correction, where appropriate, for multiple comparisons. The relative risk (RR) associated with the presence of an antigen for the development of multiple sclerosis was calculated using the formula of Svejgaard $e t^{16}$ :

$$
\mathbf{R R}=\frac{\text { Antigen }+/ \mathbf{M S}}{\text { Antigen }-/ \text { MS }} \times \frac{\text { Antigen }-/ \text { control }}{\text { Antigen }+/ \text { control }}
$$


Table 1 HLA antigen frequencies in Caucasoid controls and multiple sclerosis patients in Wellington

\begin{tabular}{|c|c|c|c|c|c|}
\hline Antigen & $M S(\%)$ & Controls (\%) & $R R$ & $\chi^{2}$ & p-value \\
\hline $\begin{array}{l}\text { DR2 } \\
\text { DQw1 }\end{array}$ & $\begin{array}{l}67 \\
82\end{array}$ & $\begin{array}{l}23 \\
58\end{array}$ & $\begin{array}{l}6 \cdot 9 \\
3 \cdot 3\end{array}$ & $\begin{array}{l}50 \cdot 8 \\
17.9\end{array}$ & $\begin{array}{l}<0.001 \\
<0.001\end{array}$ \\
\hline
\end{tabular}

\section{Results}

(1) Comparison of Caucasoid controls and multiple sclerosis patients (table 1)

There was a significant excess of both DR2 and DQw1 in multiple sclerosis patients. The association with DR2 ( RR $\left.=6.9, \chi^{2}=50.8, p<0.001\right)$ was stronger than that with DQw1 $\left(\mathrm{RR}=3.3, \chi^{2}=17.9\right.$, $\mathrm{p}<0.001)$.

All DR2 positive subjects were also DQw1 positive. Only $15 \%$ of multiple sclerosis patients were DQw1 positive/DR2 negative, whereas this antigen combination was seen in $35 \%$ of controls. For the subgroup of DR2 negative individuals, the frequency of DQw1 was almost the same in multiple sclerosis patients and Caucasoid controls (multiple sclerosis: $21 / 47,45 \%$; controls: $41 / 90,46 \% ; \chi^{2}=0.01$, NS).

\section{(2) Comparison of Caucasoid and Maori controls (table 2)}

DQw1 was present in $58 \%$ of Caucasoid and $55 \%$ of Maori controls $\left(\chi^{2}=0 \cdot 2, \mathrm{NS}\right)$. As has been previously reported, ${ }^{2}$ DR2 was more prevalent in Caucasoids than in Maoris, although for the groups in the present study, this difference was not statistically significant $\left(24 \%\right.$ versus $13 \%, \chi^{2}=2 \cdot 9$, NS). In Maoris, there were significantly higher frequencies of DR5 and DQw3, and lower frequencies of DR3 and DQw2.

\section{(3) Comparison with Cardiff and Aberdeen studies (table 3)}

The DR2 and DQw1 frequencies for Wellington multiple sclerosis patients and Caucasoid controls were compared with those obtained from recent studies centred in Aberdeen ${ }^{10}$ and Cardiff..$^{12}$

(a) DR2. In multiple sclerosis patients, there was a higher frequency of DR2 in Wellington $\left(\chi^{2}=11 \cdot 3\right.$, degrees of freedom $(\mathrm{df})=2, \mathrm{p}=0.004)$. In controls, there was a higher frequency of DR2 in Aberdeen

Table 2 HLA antigen frequencies in Caucasoid and Maori controls in Wellington

\begin{tabular}{lllll}
\hline Antigen & Caucasoid (\%) & \multicolumn{2}{l}{ Maori $(\%) \chi^{2}$} & $p$-value \\
\hline DR2 & 23 & 13 & 2.6 & NS \\
DQw1 & 58 & 55 & 0.2 & NS \\
DR3 & 32 & 6 & 19.8 & $<0.001$ \\
DR5 & 15 & 56 & 38.5 & $<0.001$ \\
DQw2 & 52 & 11 & 35.8 & $<0.001$ \\
DQw3 & 56 & 83 & 15.4 & $<0.001$ \\
\hline
\end{tabular}

Table 3 Frequency of Class II HLA antigens in Caucasoid controls and multiple sclerosis patients and prevalence of multiple sclerosis in Wellington, Cardiff and Aberdeen

\begin{tabular}{lccc}
\hline & Aberdeen & Cardiff & Wellington \\
\hline $\begin{array}{l}\text { Prevalence of multiple sclerosis } \\
\text { (per } 10^{5} \text { ) }\end{array}$ & 178 & 113 & 58 \\
$\begin{array}{l}\text { Frequency of DR2 } \\
\text { Multiple sclerosis }\end{array}$ & $49 \%$ & $51 \%$ & $67 \%$ \\
Controls & $41 \%$ & $27 \%$ & $23 \%$ \\
RR & 1.4 & 2.9 & 6.9 \\
p-value & $\mathrm{NS}$ & $<0.001$ & $<0.001$ \\
Frequency of DQwI & $77 \%$ & $71 \%$ & $82 \%$ \\
Multiple sclerosis & $62 \%$ & $59 \%$ & $58 \%$ \\
Controls & $2 \cdot 1$ & $1 \cdot 7$ & 3.3 \\
RR & $<0.006$ & $\mathrm{NS}$ & $<0.001$ \\
p-value & & & \\
\hline
\end{tabular}

$\left(\chi^{2}=10 \cdot 7 . \mathrm{df}=2, \mathrm{p}=0.005\right)$.

(b) $D Q w 1$. In multiple sclerosis patients, the frequency of DQw1 was not significantly different between the three regions $\left(\chi^{2}=2 \cdot 6, \quad \mathrm{df}=2\right.$, $p=0.28)$. DQwl was present with a remarkably similar frequency in the three control populations.

\section{Discussion}

This study confirms previous ones in showing that both DR2 and DQw1 are associated with multiple sclerosis in Caucasoid populations. Although the frequency of $\mathrm{DQw1}$ positive cases was higher thano DR2 positive ones, the association with DR2 was seen to be more significant when compared with the control? population.

In the present study the association of multiple sclerosis with DQw1 appears to be secondary to the known linkage disequilibrium of this antigen with DR2, rather than a primary association. Thus, in DR2 negative multiple sclerosis patients, there was no excess of $D Q w 1$. It is also notable that $D Q w 1$ was seen with a high frequency in Maori controls, a population with a very low risk for multiple sclerosis despite living in a high risk temperate region.

A stronger association of multiple sclerosis with DR2 (than with DQw1) was also found in Cardiff. ${ }^{12}$ However, in Aberdeen, the stronger association was with DQw1 $1 .^{10}$ The lack of an association with DR2 in the latter study was largely due to an unusually high frequency of DR 2 in the normal population. Indeed, a correlation has been demonstrated between the regional prevalence of multiple sclerosis in the United Kingdom and the frequency of DR2 in the normal population. $^{17}$

It has been argued that there is a single multiple sclerosis susceptibility gene on the sixth chromosome in linkage disequilibrium with the HLA system. ${ }^{1819}$ If this hypothesis is true, the present results suggest that the putative gene is closer to the DR than the DQ locus and that DR2 is currently the best marker for that gene. 
Alternatively, as Swingler et al have pointed out, ${ }^{12}$ the HLA findings in multiple sclerosis may be interpreted by considering that multiple sclerosis susceptibility is related to multiple genetic and environmental factors. Such a multifactorial hypothesis would allow for the lack of association of multiple sclerosis and DR2 in certain populations, ${ }^{13}$ different HLA associations in some non Caucasoid populations, ${ }^{20}$ a high frequency of DR2 in some populations in which multiple sclerosis is rare, ${ }^{21}$ and the occurrence of other genetic associations unrelated to the HLA system. ${ }^{22}$

Swingler et al ${ }^{12}$ have discussed the multifactorial hypothesis in terms of multiple risk factors of varying importance. A high frequency of major risk factors in a population will result in a high prevalence of the disease. However, that same high frequency of major risk factors may actually obscure their association with the disease in such a population. Associations may be seen instead with more minor risk factors. Conversely, when major risk factors are less common in a population, the disease prevalence will be less, but the major risk factors will show the strongest associations with the disease.

If we assume that there are multiple risk factors of varying importance predisposing to the development of multiple sclerosis, it might be concluded from the studies of Class II HLA antigens summarised in table 3 that the association with DR2 is of major importance at least in Caucasoid populations. Thus, in Aberdeen where the prevalence of multiple sclerosis is $178 / 10^{5}$, DR2 is weakly associated with multiple sclerosis because of its high frequency in the normal population; in Cardiff, where the prevalence of multiple sclerosis is two thirds that of Aberdeen, a stronger and statistically significant association with $D R 2$ is seen; in Wellington, where the prevalence of multiple sclerosis is one third that in Aberdeen, the strongest association of DR2 with multiple sclerosis is seen.

Overall, only a small proportion of the total DR2 positive population actually develops multiple sclerosis. It seems likely therefore that there are other risk factors of major importance for the development of multiple sclerosis which are as yet undetermined.

The study was supported in part by a grant from The New Zealand Multiple Sclerosis Society. Mr G Purdie helped with statistical analysis.

\section{References}

1 Detels R, Visscher BR, Malmgren RM, Coulson AH, Lucia MV, Dudley JP. Evidence for lower susceptibility to multiple sclerosis in Japanese-Americans. Am J Epidemiol 1977; 105:303-10.

2 Miller DH, Hornabrook RW, Dagger J, Fong R. Ethnic and HLA patterns related to multiple sclerosis in Wellington, New Zealand. J Neurol Neurosurg Psychiatry 1986;49:43-6.

3 Ebers GC, Bulman DE, Sadovnick AD et al. A population-based study of multiple sclerosis in twins. N Engl J Med 1986; 315: 1638-42.

4 Naito S, Namerow N, Mickey MR, Terasaki PI. Multiple sclerosis: association with HL-A3. Tissue Antigens 1972;2:1-4.

5 Jersild C, Svejgaard A, Fog T. HL-A antigens and multiple sclerosis. Lancet 1972;i:1240-1.

6 Fielder AHL, Batchelor JR, Nason Vakarelis B, Compston DAS, McDonald WI. Optic neuritis and multiple sclerosis: do factor B alleles influence progression of the disease? Lancet 1981;ii: 1246-8.

7 Jersild C, Fog T, Hansen GS, Thomsen M, Svejgaard A, Dupont B. Histocompatibility determinants in multiple sclerosis, with special reference to clinical course. Lancet 1973;ii:1221-5.

8 Opelz G, Terasaki P, Myers L, et al. The association of HLA antigens A3, B7, and Dw2 with 330 multiple sclerosis patients in the United States. Tissue Antigens 1977;9:54-8.

9 Batchelor JR, Compston A, McDonald WI. The significance of the association between HLA and multiple sclerosis. Br Med Bull 1978;34:279-84.

10 Frances D, Batchelor JR, McDonald WI, et al. Multiple sclerosis in North-East Scotland. An association with HLA-DQw1. Brain 1987;110:181-96.

11 Poskanzer DC, Terasaki PI, Prenney LB, Sheridan JL, Kondy JY. Multiple sclerosis in the Orkney and Shetland Islands. III. Histocompatibility determinants. J Epidemiol Community Health 1980;34:253-7.

12 Swingler RJ, Kirk PF, Darke C, Compston DAS. HLA and multiple sclerosis in south east Wales. $J$ Neurol Neurosurg Psychiatry 1987;50:1153-5.

13 Al-Din ASN, al-Saffar M, Siboo R, Behbehani K. Association between HLA-D region epitopes and multiple sclerosis in Arabs. Tissue Antigens 1986;27:196-200.

14 Skegg DCG, Corwin PA, Craven RS, Malloch JA, Pollock M. Occurrence of multiple sclerosis in the north and south of New Zealand. J Neurol Neurosurg Psychiatry 1987;50:134-9.

15 McDonald WI, Halliday AM. Diagnosis and classification of multiple sclerosis. Br Med Bull 1977;33:4-8.

16 Svejgaard A, Hauge M, Jersild C, et al. The HLA system: an introductory survey. In: Beckman L, Hauge M, eds. Monographs in Human Genetics vol 7. Basel: Karger, 1975:1-103.

17 Swingler RJ, Compston DAS. The distribution of multiple sclerosis in the United Kingdom. J Neurol Neurosurg Psychiatry 1986;49:1115-24.

18 Terasaki PI, Mickey MR. A single mutation hypothesis for multiple sclerosis based on the HLA system. Neurology 1976; 26:56-8.

19 Stewart GJ, McLeod JG, Basten A, Bashir AV. HLA family studies and multiple sclerosis: a common gene dominantly expressed. Hum Immunol 1981;3:13-29.

20 Kurdi A, Ayesh I, Abdallat A, et al. Different B lymphocyte alloantigens associated with multiple sclerosis in Arabs and North Europeans. Lancet 1977;i:1123-5.

21 Gyodi E, Tauszik T, Petranyi G, et al. The HLA antigen distribution in the Gipsy population in Hungary. Tissue Antigens 1981;18:1-12.

22 Pandey JP, Goust J-M, Salier J-P, Fudenberg HH. Immunoglobulin $\mathrm{G}$ heavy chain $(\mathrm{Gm})$ allotypes in multiple sclerosis. $J$ Clin Invest 1981;67:1797-800. 